\title{
Notas inferenciais sobre o encargo e as diretrizes poéticas em 0 Jardim de Rubiane Maia
}

\author{
[Rubiane Maia: 0 Jardim, Terra Comunal \\ - Marina Abramović + MAI, Sesc Pompeia, São Paulo, Brasil]
}

Lindomberto Ferreira Alves *

http://dx.doi.org/10.22409/poiesis. 2033.437-452

\section{Encargo ${ }^{1}$}

A performance O Jardim (2015), da artista multimídia contemporânea brasileira Rubiane Maia, objeto desta resenha crítica, trata-se de um trabalho especificamente concebido por ela, a convite das curadoras Paula Garcia e Lynsey Peisinger, para compor o projeto "Oito performances", da exposição Terra Comunal - Marina Abramović + MAI 2, aberta à visitação de março a maio de 2015, no Sesc Pompeia, São Paulo/SP, Brasil. Rubiane Maia foi uma dos oito artistas brasileiros selecionados por Marina Abramović e pelas curadoras da exposição

\footnotetext{
* Lindomberto Ferreira Alves é artista-educador, arquiteto-urbanista e pesquisador. É mestrando em Teoria e História da Arte no Programa de Pós-Graduação em Artes (PPGA) da Universidade Federal do Espírito Santo, licenciando em Artes Visuais pelo Centro Universitário Araras Dr. Edmundo Ulson - UNAR/SP e bacharel em Arquitetura e Urbanismo pela Faculdade de Arquitetura e Urbanismo da Universidade Federal da Bahia. Atua como arte-educador no Centro Cultural Sesc Glória, Vitória, ES, Brasil. E-mail: lindombertofa@gmail.com; ORCID: https://orcid.org/0000-0001-78321734.
} 
para realizar performances autorais de longa duração, nesta que foi uma das maiores retrospectivas já realizada sobre a carreira da aclamada artista sérvia Marina Abramović, que é responsável por consolidar a performance com uma forma autônoma de arte ao introduzir novos conceitos no campo, como reperformance e performance de longa duração.

Em entrevista concedida por Rubiane Maia, em 2015, a Aline Alves, do portal capixaba Sou ES, na época da realização da exposição, a artista conta que recebeu o convite para apresentar seu portfólio em dezembro de 2013. Recordando o momento, Rubiane Maia lembra que, inicialmente, ficou surpresa e curiosa com o convite, sobretudo pela possibilidade de a artista conhecer pessoalmente Marina Abramović, bem como de ouvir as impressões da artista sérvia sobre seu trabalho. Entretanto, a confirmação de que faria parte da exposição só veio um ano depois, em 2014. Foi só então que Rubiane Maia começou a pensar em uma performance que pudesse acontecer em um contexto de total imersão, afinal de contas, até então, segundo acrescenta a artista, ela nunca havia realizado uma performance tão longa.

Todavia, antes mesmo da abertura da exposição, Rubiane Maia teria de participar juntamente com os demais artistas brasileiros selecionados ${ }^{3}$ para integrar a mostra do workshop Cleaning the House ${ }^{4}$, ministrado por Marina Abramović, como parte das atividades de préprodução de Terra Comunal - Marina Abramović + MAI. Assim, os artistas foram convidados a realizar o Método Abramović em meio à natureza - em um sítio em Jequitibá, interior do estado de São Paulo. O método consistiu basicamente em permanecer em silêncio e em jejum, durante cinco dias, intercalando exercícios que aliavam concentração, resistência e autocentramento. O objetivo do workshop, como o próprio nome insinua, consistia em limpar os corpos e as mentes dos artistas, trabalhando os limites de cada um, no intuito de prepará-los para as performances de longa duração que realizariam durante os dois meses em que a exposição estaria em cartaz.

Na mesma entrevista, Rubiane Maia revela que uma primeira versão desse trabalho - a performance Jardín secreto - porque deseo $\mathrm{crer}^{5}$ - foi apresentado inicialmente em 2012, na Espanha. Naquele ano, o trabalho foi realizado no âmbito de uma residência artística. Durante cerca de trinta dias, Rubiane Maia se propôs a cultivar feijões, cuidando e acompanhando

Poiésis, Niterói, v. 20, n. 33, jan./jun. 2019. 
o crescimento de todos, dia a dia. Isolada em um estúdio, a artista permaneceu praticamente sozinha e boa parte do tempo em silêncio, ora regando-os, semente por semente, com um pequeno conta-gotas; ora sentada, observando e fotografando os deslocamentos dos feijoeiros que cresciam em busca da luminosidade que adentrava no estúdio por uma janela. Chegado o "fim" do processo, o jardim foi transferido do estúdio e montado em uma sala, com o chão recoberto por uma camada bem espessa de algodão. Na entrada da sala, aberta então à visitação do público, há o seguinte convite: "entre descalço". Ao adentrar no espaço, além de poder verificar os elementos que estiveram presentes ao longo do processo de cultivo dos feijões - como a mesa branca utilizada todos os dias, os pratos, a taça com água e o contagotas - o público podia presenciar uma pequena fração do tempo de cuidado da artista com seu jardim, que silenciosamente continuava a crescer junto com ele.

Nota-se, portanto, que sendo os encargos de uma obra os aspectos relacionados à motivação que esse objeto artístico busca atender (BAXANDALL, 2006), no caso da performance $O$ Jar$\operatorname{dim}$ (2015), apesar do encargo, isto é, do padrão de intenção ser o mesmo de Jardín secreto - porque deseo crer - a saber, chamar atenção à incapacidade de percebermos a olho nu as minúcias, as formas e as transformações contínuas do desenvolvimento da vida - de acordo com a artista, as condições para sua realização durante a exposição Terra Comunal - Marina Abramović + MAI eram outras, distintas de 2012. Haveria muitos elementos novos e, consequentemente, os desafios que esses novos elementos lançaram levaram a artista a considerar uma série de outras estratégias à realização da performance $O$ Jardim (2015), tais como a incorporação da presença do público ao processo, o plantio em grande escala dos feijões na terra e o uso adicional de luz artificial. Nestes termos, conta Rubiane Maia que seria preciso criar as circunstâncias mínimas necessárias para que os feijoeiros pudessem se desenvolver e crescer da melhor maneira possível em meio a uma arquitetura cinza, de puro concreto, da sede do Sesc Pompéia, na cidade de São Paulo. 

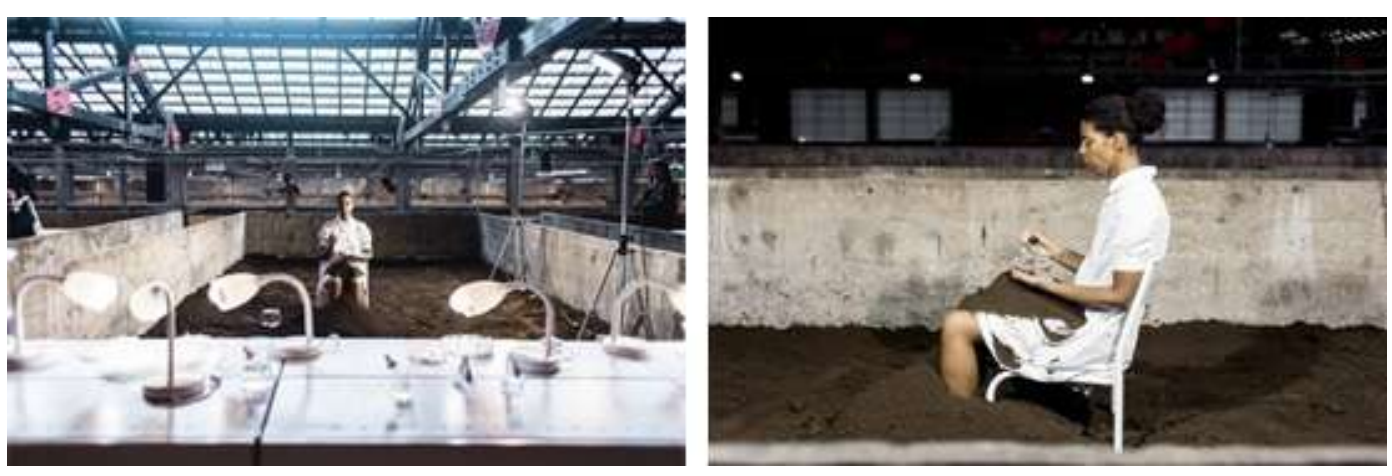

Poiésis, Niterói, v. 20, n. 33, jan./jun. 2019. 


\section{Diretrizes ${ }^{6}$}

Nesse contexto, a performance $O$ Jardim (2015), apresentada em São Paulo, Brasil, durante a exposição Terra Comunal - Marina Abramović + MAI, consistiria em cultivar uma pequena plantação de feijões em meio ao Centro Cultural Sesc Pompeia. Durante dois meses, Rubiane Maia permaneceria oito horas por dia em silêncio, fomentando as condições mínimas ao plantio, bem como acompanhando todo o processo de crescimento dos feijoeiros - desde a preparação da terra, passando pelas diferentes fases do ciclo de desenvolvimento da planta: o brotar, o nascer, o crescer, o viver, o morrer - até que se constituísse o jardim.

Tão importante quanto entender o encargo de uma obra, ou seja, o que a motivou em uma escala mais ampla, é elucidar suas diretrizes, isto é, os elementos e as questões específicas daquela obra que a condicionaram daquele jeito. (BAXANDALL, 2006) Conforme descrito no press-realese ${ }^{7}$ deste trabalho, a performance $O$ Jardim exigiria uma série de práticas e operações sensíveis que variaram entre o que há de mais simples (como o cuidado, a observação e as pesquisas diárias) e de mais complexos (como a dedicação total e irrestrita da artista ao processo, as interferências externas à mostra - uma vez que as funções habituais do Centro Cultural Sesc Pompéia seriam mantidas - a presença e participação do público, a remoção de uma grande quantidade de solo fértil, o controle da umidade indoor, a instalação apropriada de luminosidade complementar, dentre outros). Nota-se aí que a reperformance de Jardín secreto - porque deseo crer (2012) só foi possível de ser realizada, em 2015, sob o nome de $O$ Jardim graças às adequações ao contexto da exposição em questão.

Entretanto, em outra entrevista concedida por Rubiane Maia, também no ano de 2015, a Ulisses Carrilho, para o Marina Abramović Institute - MAI, a artista disse que, em virtude de sua inexperiência com o plantio nessas condições, ela teve que descobrir o que seria necessário fazer para que os feijões crescessem dentro de um espaço fechado, o que, de acordo com suas pesquisas, não seria exatamente adequado para seu desenvolvimento. Rubiane revela também que foi a partir de algumas pistas oriundas dessas investigações que se deu a escolha do espaço onde o trabalho seria realizado, a saber, nas chamadas Salas de Estar do Centro Cultural, em lajes de concreto, dentro de um grande galpão, razoavelmente arejado e 
dotado de esquadrias que deixavam adentar no espaço interno luz natural. Muito embora houvesse um fluxo intenso de visitantes, os que ali estavam não se restringiam à exposição em si e partilhavam o silêncio, a concentração e a observação, aspectos intrínsecos do espaço onde a performance foi realizada, que congregava, dentre outras funções, pesquisa, estudo, leituras e jogos de xadrez. A artista acrescenta, ainda, que o resultado formal dependeria, além da performance, da confluência de todos os aspectos inerentes ao espaço escolhido.

Nesse novo contexto, $O$ Jardim foi concebido como uma espécie de laboratório vivo em constante processo de transformação para experiências de cultivo e plantio. Se em 2012, Jardín secreto - porque deseo crer nasceu a partir de pesquisas sobre como plantar dentro de casa, em 2015, O Jardim se instaurou como possibilidade de investigação sobre a conexão antes estabelecida entre o brotar e o observar a vida nascendo em uma escala muito mais complexa. Nestes termos, o objetivo do trabalho residiria e poderia ser assim descrito exatamente na criação de um local onde a vida pudesse ser continuamente manipulada, testada, cuidada e observada - do nascimento à morte.

Com a atenção voltada para esse pequeno microcosmo, que inevitavelmente produziria certa desfamiliarização espaço-temporal em função da sua interferência no espaço arquitetônico, o público de $O$ Jardim, por sua vez, seria convidado a acompanhar o processo, que se alteraria de maneira lenta, quase imperceptível, todos os dias. Experimentaria, assim, uma espécie de vínculo, de cumplicidade; afinal de contas, dada a inaptidão salutar do olho de não perceber tudo - neste caso, o crescimento do feijão a olho nu até se tornar jardim - a performance despertaria o desejo de retorno, bem como uma maior atenção e curiosidade pela apreciação do processo em si e das questões conceituais e existenciais que a partir dele seriam suscitadas. Assim, o que nos atravessa enquanto espectadores é a própria experiência estética vivenciada pela artista, que coloca a formalização estética do ato vivencial, manifestada pelo crescimento dos feijões diante do real, não somente para construir sua obra, como, também, para modificar seu próprio ser, sua própria vida.

Poiésis, Niterói, v. 20, n. 33, jan./jun. 2019. 

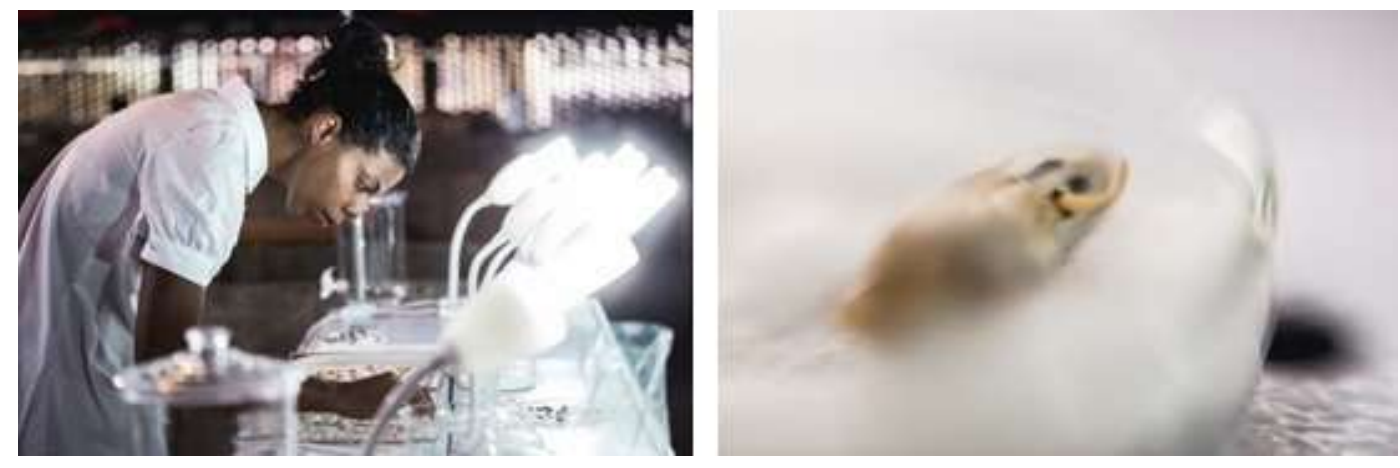

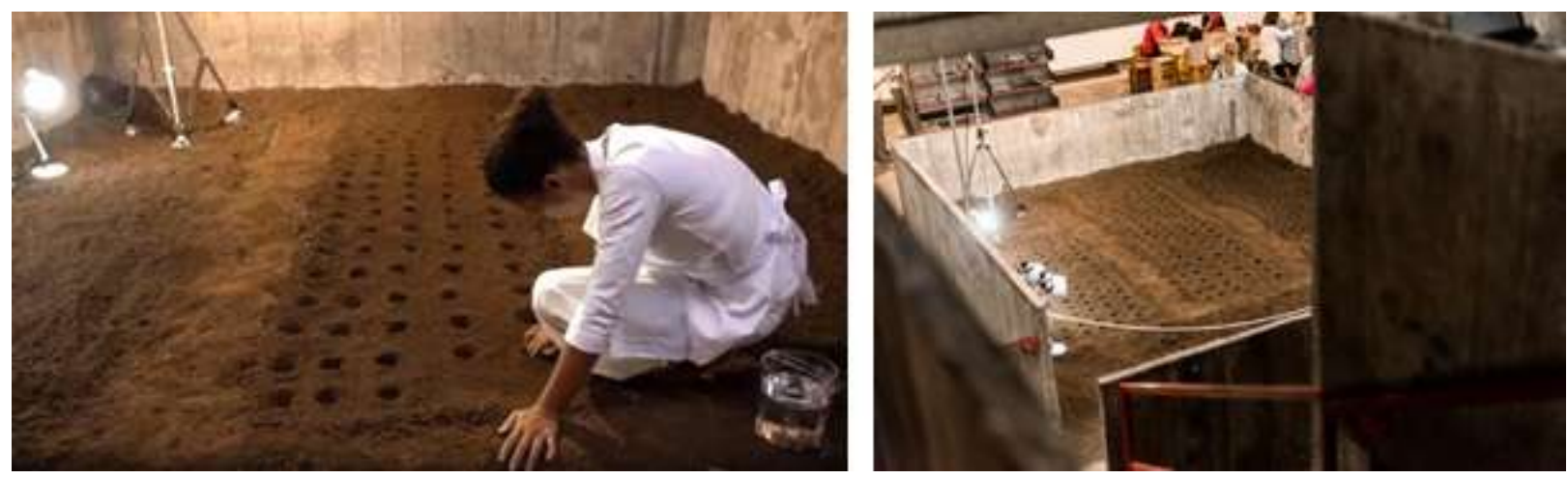

Poiésis, Niterói, v. 20, n. 33, jan./jun. 2019. 


\section{Tendências e intencionalidades poéticas}

Em 2019, prestes a completar treze anos de carreira, notadamente marcada e interessada na criação e na invenção de outros modos de percepção e de relação com a vida, guardadas as devidas nuances poéticas exploradas por Rubiane Maia durante a realização da performance $O$ Jardim, parece haver, entre as múltiplas estratégias performativas que atravessam este e os cerca de sessenta outros trabalhos produzidos no decorrer de sua trajetória artística, um elo magnético e invisível, uma espécie de resiliência silenciosa que os mantém conectados. Trata-se de trabalhos que, no seu conjunto, não se eximem em explorar a capacidade da arte na contemporaneidade de se manifestar como laboratório ético, poético e político do sensível, suscitando não só na artista, mas também no público, outras formas de experimentar ou experienciar novas relações com o outro, com o espaço, com o tempo; em suma, com a própria vida.

Por um lado, suas proposições parecem ter como tendência o poder inquietante e provocador que a explosão da obra na vida promove à arte, ou seja, a instauração de uma experiência artística "[...]que dê conta das maneiras de viver, da arte de viver". (FAVARETTO, 2011, p. 108) Por outro, com o foco de investigação voltado para formas de criação em processo buscando sempre lidar com o universo temporal-espacial e, principalmente, afetivo - as experiências decorrentes de suas reflexões sobre as relações entre arte e vida evidenciam uma estética cuja intencionalidade é fazer uso do corpo para "ampliar suas possibilidades de percepção para além do habitual, por meio de uma constante (re)elaboração de sua própria noção de território existencial (espacial, temporal, social, cognitivo etc.)." ${ }^{18} \mathrm{Em}$ outras palavras, ao colocar vida e obra no mesmo plano de contágio, suas performances, em maior ou em menor grau, instauram uma outra relação estética entre arte e vida, convocando o corpo "a ampliar sentidos em direção ao esgarçar de seus contornos". (MACHADO, 2015, p. 1)

Como vimos, por interposição do inventário do encargo e das diretrizes da performance $O$ Jardim, podemos afirmar que ela não escapa a esse padrão de intenção: extrair o poético da vida, requisitando do público outro tipo de percepção sensível sobre os atravessamentos entre arte e vida. No caso de $O$ Jardim, a performance parece se dar entre ela, a artista, e o 
jardim, ou seja, é a própria vida - através do crescimento dos feijões - que é objeto de/da performance. Indo além, podemos dizer que são os próprios feijoeiros que performam no trabalho - quando observados, por exemplo, os desenhos contidos nos fragmentos dos seus diários que tentam capturar e registrar o movimento da vida crescendo. Segundo Rubiane Maia, "plantar, colher, cuidar de um jardim, pode ensinar bastante, não apenas sobre a vida, mas, sobretudo, sobre a morte - no sentido de se estar lidando com a delicadeza da vida"' Neste sentido, a artista acrescenta ainda que os feijões tanto poderiam crescer e constituir o jardim quanto poderiam morrer a qualquer momento. Rubiane Maia ressalta, por fim, que, dada essas circunstâncias e suas contingências, seria necessário aprender a superar as frustações da perda e aprender a lidar, a cada dia, com um processo que nasce, cresce, vive, morre e nasce de novo, dia após dia. Mas o que restaria à artista? À artista resta a observação, o autocentramento, o silêncio, o tempo de cuidado. Ao lançar-se para fora dos enquadres, Rubiane Maia, nesta performance, redefine sutilmente o foco de atenção para o ciclo de vida dos feijões; assumindo como matéria de expressão artística, como obra de arte, a própria natureza instável, efêmera, minuciosa, frágil e misteriosa da existência.

Se algo tem um encargo, uma motivação, ou seja, uma causa pessoal, artística e/ou históri$\mathrm{ca}$, na verdade a tem porque se trata de uma resposta a uma determinada configuração de um contexto social e subjetivo. (BAXANDALL, 2006) Nota-se aí, portanto, que o projeto poético e estético desta performance parece estar estritamente vinculado ao panorama da vida contemporânea e à inclinação de aproximação aos trabalhos que tem como padrão de intenção a alteridade e a referência às paisagens psicossociais da contemporaneidade. Trabalhos que não apenas partem do pressuposto da "arte como possibilidade do encontro entre modos de vida e produção de subjetividades" (SILVA, 2011, p. 24), como também assumem a dimensão da relação arte e vida como "vivência partilhada, em um apelo estético que convida à diluição dos contornos juntos à potência de criação". (SILVA, 2011, p. 76) Em outra entrevista concedida por Rubiane Maia, em 2016, a Patricia Galleto, do site capixaba Dança no ES, a artista conta que as contaminações entre arte e vida produzem um modo de pensar e produzir favorável às linhas de resistência de um mundo-crise, tencionando um diálogo ético, estético e político que evocam novas corporeidades - uma forma de repensar uma política da

Poiésis, Niterói, v. 20, n. 33, jan./jun. 2019. 
vida que se afirme na potência de existir. Ainda segundo ela, sua aposta na arte passa essencialmente pela ideia de micropolítica, de disseminação e de contágio, sobretudo a partir das potências que são deflagradas através dos encontros - pequenos momentos onde conseguimos compartilhar uns com os outros nossas descobertas, inquietações, frustações e esperanças.

Deslizando por certo limbo epistemológico ${ }^{10}$, em grande medida, ainda desconhecido - que renuncia a herança da radicalidade utópica das vanguardas, bem como a condição sine qua non de existência da arte atual pautado no liberalismo hedonista contemporâneo - parece ser nas sutilezas com que $O$ Jardim, de Rubiane Maia, desperta no público a reflexão sobre a atenção ao cuidado com os nossos próprios modos de vida, que talvez esteja incutida a efetividade de um tipo de simbolização e de cognição não alienada entre arte e vida, diversa da condição atual em que a lógica espetacular da arte se confunde com a realidade. 

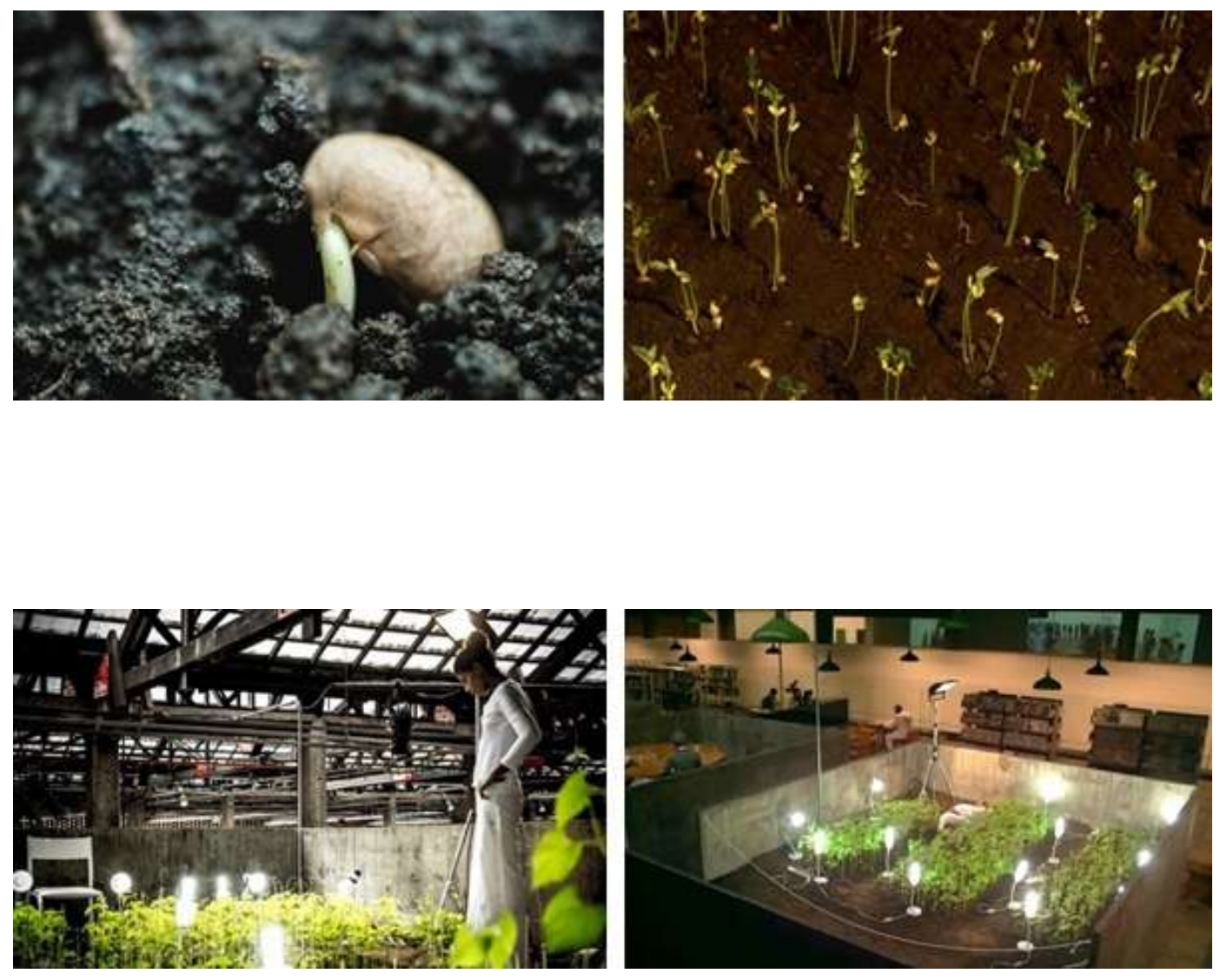

Poiésis, Niterói, v. 20, n. 33, jan./jun. 2019. 


\section{Notas}

${ }^{1}$ De acordo com as reflexões oriundas da crítica inferencial proposta por Michael Baxandall no livro Padrões de Intenção: a explicação histórica dos quadros (2006), seria possível compreender um objeto artístico a partir das contingências históricas de sua criação, por meio de um procedimento de exame do processo criativo atento às suas motivações (encargo) e aos seus aspectos formais (diretrizes). Assim, no âmbito da discussão estabelecida por Baxandall (2006), a noção de encargo diria respeito às motivações que teriam levado um dado artista à concepção de determinado objeto de arte. Os encargos tratar-se-iam, portanto, das circunstâncias que conduziriam um artista a desejar produzir um projeto artístico específico.

${ }^{2}$ Promovido pelo Marina Abramović Institute, a exposição em questão tratou-se da maior apresentação retrospectiva do conjunto da obra da artista sérvia e performer Marina Abramović. Fundado por Marina Abramović, em 2010, durante a exposição retrospectiva intitulada The Artist is Present, em Nova York, o Marina Abramović Institute - MAl é um instituto itinerante de arte dedicado à arte imaterial, especialmente à arte da performance. Para mais informações sobre o instituto criado e gerido pela artista sérvia, acessar https://mai.art/about-mai/.

${ }^{3}$ Os demais artistas brasileiros que integraram, junto com Rubiane Maia, o projeto Oito performances durante a exposição Terra Comunal - Marina Abramović + MAl, em São Paulo, no Sesc Pompeia, entre 10/3/2015 e 10/5/2015, foram: os integrantes do Grupo EmpreZa, Ayrson Heráclito, Fernando Ribeiro, Maikon K, Marco Paulo Rolla, Maurício lanês e Paula Garcia.

${ }^{4} \mathrm{O}$ workshop começou a ser desenvolvido por Marina Abramović no decurso dos seus anos de atuação como professora, no âmbito da Hochschule fur Bildende Kunst, em Hamburgo, na Alemanha; da Ecole des Beaux Arts, em Paris, na França; e da Hochschule fur Bildende Kunst, em Braunschweig, na Alemanha. Desde a década de 1980, a artista sérvia passou a estruturar uma série de oficinas para seus alunos intituladas Cleaning the House, cuja premissa parte da ideia de corpo como uma casa, segundo o qual os participantes desafiam os limites físicos e mentais do seu próprio corpo, forçando-o a responder e se reconectar com o seu ambiente. Trata-se, assim, de um treinamento no qual o corpo passa a desenvolver um método de autoconsciência para si mesmo. 0 workshop, que hoje é promovido pelo Marina Abramović Institute, aberto à participação do público em geral, busca promover uma coletividade de sentidos por meio de uma rigorosa redução dos estímulos aos quais os corpos estão constantemente submetidos. Por meio de trocas energéticas geradas a partir do simples contato humano, o treinamento convoca o corpo à introspecção, levando-o, consequentemente, a uma expansão do estado de clareza de si. Para mais informações sobre o método concebido por Marina Abramović, acesse https://mai.art/cth2019/.

${ }^{5}$ A performance em questão foi desenvolvida durante a realização de uma residência artística no âmbito da Cal Gras - Alberg de Cultura e Residência Artística, sediada em Avinyó, Barcelona-Espanha, e apresentada entre 1 de outubro e 4 de novembro de 2012. Para mais informações sobre a performance Jardín secreto - porque deseo crer (2012), de Rubiane Maia, acessar http://cargocollective.com/rubianemaia/jardin-secreto-porque-deseo-creer.

${ }^{6}$ Ainda segundo Baxandall (2006), a noção de diretrizes diria respeito aos aspectos formais que um dado artista teria que considerar para materializar determinado objeto de arte. As diretrizes tratar-se-iam, portanto, das condições mínimas necessárias que conduziriam um artista à execução dos processos criativos e estéticos de um projeto artístico específico.

${ }^{7}$ Texto de apresentação e de divulgação da performance $O$ Jardim (2015), realizada durante a exposição Terra Comunal - Marina Abramović + MAI. Sesc Pompéia, São Paulo, Brasil, de 9 de março a 10 de maio de 2015. Para acessar o realese do trabalho na íntegra: http://cargocollective.com/rubianemaia/o-jardim. 
${ }^{8}$ Este pequeno trecho é parte do statement, espécie de carta de intenções que sintetiza a proposta artística de Rubiane Maia. O statement na íntegra pode ser acessado na homepage da artista: http://cargocollective. com/rubianemaia.

9 Trecho do depoimento de Rubiane Maia sobre a performance O Jardim (2015) para o vídeo promocional da exposição Terra Comunal - Marina Abramović + MAl. Para acessar o vídeo promocional do trabalho na íntegra: https:// www. youtube.com/watch?v=pj7iPi05nag\&t $=16 \mathrm{~s}$.

${ }^{10}$ Segundo Agamben (2013, p. 352), hoje, "a expressão obra de arte tornou-se opaca ou mesmo ininteligível. A sua obscuridade não diz respeito apenas ao termo arte, que dois séculos de reflexão estética tornaram problemático, mas também, e acima de tudo, ao termo obra. Até mesmo de um ponto de vista gramatical a expressão obra de arte, que usamos com tanta desenvoltura, não é nada fácil de entender. De fato, não está claro se, por exemplo, trata-se de um genitivo subjetivo, isto é, se a obra é feita da arte, pertence à arte, ou de um genitivo objetivo, no qual o importante é a obra e não a arte. Em outras palavras, se o elemento decisivo é a obra, a arte, ou a não bem definida mistura das duas. Além disso, [...] hoje a obra parece atravessar uma crise decisiva que a fez desaparecer do âmbito da produção artística, na qual a performance e a atividade criativa do artista tendem cada vez mais a tomar o lugar daquilo a que estávamos habituados a chamar obra de arte".

\section{Referências}

AGAMBEN, Giorgio. Arqueologia da obra de arte. Princípios, Natal, v. 20, n. 34, pp. 349-361, jul.-dez. 2013.

BAXANDALL, Michael. Padrões de Intenção: a explicação histórica dos quadros. São Paulo: Ed. Cia da Letras, 2006.

FAVARETTO, Celso Fernando. Deslocamentos: entre a arte e a vida. ARS, São Paulo, v. 9, n. 18, pp. 94-109, jan. 2011.

MACHADO, Leila Aparecida Domingues. Performar. MARTINS, Júlio (Org.). Catálogo: MODOS DE USAR. Vitória: Museu de Arte do Espírito Santo Dionísio Del Santo \& Funcultura - Secretaria da Cultura do Governo do Estado do Espírito Santo, 2015, pp. 145-147.

O JARDIM | Rubiane Maia | 8 performances | Terra Comunal - Marina Abramović + MAI. Direção: Felipe Lima. São Paulo: Mão Direita, 2015. 1 vídeo (3 min 31 s). Casa Redonda. Disponível em https://www.youtube.com/watch?v=dD8pLAbfX30\&t=32s. Acesso em 27 dez. 2017.

Poiésis, Niterói, v. 20, n. 33, jan./jun. 2019. 
SILVA, Rubiane Vanessa Maia da. Artista capixaba participa de mostra de Marina Abramović em SP. [Entrevista cedida a] Aline Alves. Portal Sou ES, Vitória, 20 fev. 2015. Disponível em http://www.soues.com.br/plus/modulos/noticias/ler.php?cdnoticia=1830. Acesso em $27 \mathrm{dez}$. 2017.

SILVA, Rubiane Vanessa Maia da. Discreet Harvest: An Interview with Artist Rubiane Maia. [Entrevista cedida a] Ulisses Carrilho. Marina Abramović Institute - MAI, São Paulo, 09 mai. 2015. Disponível em https://mai.art/terra-comunal-content/2015/5/9/open-field. Acesso em 27 dez. 2017.

SILVA, Rubiane Vanessa Maia da. O Jardim. In: SILVA, Rubiane Vanessa Maia da. Homepage Rubiane Maia, [S. I.], 2015. Disponível em http://cargocollective.com/rubianemaia/o-jardim. Acesso em 27 dez. 2017.

SILVA, Rubiane Vanessa Maia da. $3^{\circ}$ Dança na Roda: encontro de linguagens em bate-papo com Rubiane Maia e Carla Van Den Bergen encerra o Dança na Roda. [Entrevista cedida a] Patricia Galleto. Site Dança no ES, Vitória, 13 de mai. 2016. Disponível em http://www. dancanoes.com.br/2016/05/. Acesso em 29 jan. 2019.

SILVA, Rubiane Vanessa Maia da. Devios, sobre arte e vida na contemporaneidade. Dissertação (Mestrado em Psicologia Institucional) - Programa de Pós-Graduação em Psicologia Institucional, Departamento de Psicologia, Universidade Federal do Espírito Santo, Vitória, 2011.

SILVA, Rubiane Vanessa Maia da. Statement: carta de intenções artísticas. In SILVA, Rubiane Vanessa Maia da. Homepage Rubiane Maia, [S.I., s.d.]. Disponível em http://cargocollective.com/rubianemaia. Acesso em 27 dez. 2017. 


\section{Informações das imagens:}

Fig. 1: À esquerda: Rubiane Maia, O Jardim (2015), Performance. Fotografia Vitor Nomoto. Fonte: Disponível em https://mapeamentojardinagemterritorialidade.wordpress.com/ o-jardim-rubiane-maia/. Acesso em 21 dez. 2017. À direita: Rubiane Maia, O Jardim (2015), Performance. Fotografia Victor Takayama. Fonte: Disponível em http://artishockrevista.com/2015/03/09 /sao-paulo-acoge-la-mayorretrospectiva-marina-abramovic-sudamerica/. Acesso em 21 dez. 2017.

Fig. 2: À esquerda: Rubiane Maia, O Jardim (2015), Performance. Fotografia Marina Abramović Institute. Fonte: Disponível em https://artsandculture.google.com/asset/the-garden/rAHmQ-8d3jb_0w. Acesso em 21 dez. 2017. À direita: Rubiane Maia, O Jardim (2015), Performance. Fotografia Hick Duarte, Victor Nomoto e Victor Takayama. Fonte: Disponível em https:// mai.art/terra-comunal content/2015/5/9/open-field. Acesso em $21 \mathrm{dez} .2017$.

Fig. 3: À esquerda: Rubiane Maia, O Jardim (2015), Performance. Imagem retirada do vídeo promocional da exposição Terra Comunal - Marina Abramovic + MAI. Fonte: Disponível em https://www.youtube.com/watch?v=pj7iPi05nag. Acesso em 21 dez. 2017. À direita: Rubiane Maia, $O$ Jardim (2015), Performance. Fotografia Hick Duarte. Fonte: Disponível em https:// mai.art/terracomunal-content/2015/3/23/performances-ongoing. Acesso em $21 \mathrm{dez} .2017$.

Fig. 4: À esquerda: Rubiane Maia, O Jardim (2015), Performance. Fotografia Hick Duarte, Victor Nomoto e Victor Takayama. Fonte: Disponível em https://mai.art/terra-comunal-content/ 2015/5/9/openfield. Acesso em 21 dez. 2017. À direita: Rubiane Maia, O Jardim (2015), Performance. Fotografia Rubiane Maia. Fonte: Disponível em https://mapeamento jardinagemterritorialidade.wordpress.com/ojardim-rubiane-maia/. Acesso em 21 dez. 2017.

Fig. 5: À esquerda: Rubiane Maia, O Jardim (2015), Performance. Fotografia de Carlos Rocha. Fonte: Disponível em http://www.premiopipa.com/pag/artistas/rubiane-maia-2/. Acesso em 21 dez. 2017. À direita: Rubiane Maia, O Jardim (2015), Performance. Imagem retirada do vídeo promocional da exposição Terra Comunal - Marina Abramovic + MAI. Fonte: Disponível em <https://www.youtube.com/watch?v=pj7iPi05nag. Acesso em $21 \mathrm{dez} .2017$.

Rubiane Maia, O Jardim, Terra Comunal - Marina Abramović + MAI, em exposição no Sesc Pompeia, São Paulo, Brasil de 10 de março de 2015 e 10 de maio de 2015. Curadoria de Paula Garcia e Lynsey Peisinger Mais informações: http://cargocollective.com/rubianemaia/o-jardim https://mai.art/terra-comunal

Como citar: ALVES, Lindomberto Ferreira. Notas inferenciais sobre o encargo e as diretrizes poéticas em O Jardim de Rubiane Maia [resenha crítica da mostra Rubiane Maia: O Jardim, Terra Comunal - Marina Abramović + MAI, Sesc Pompeia, São Paulo, Brasil]. Poiésis, Niterói, v. 20, n. 33, p. 437-452, jan./jun. 2019. doi: http://dx.doi.org/10.22409/poiesis.2033.437-452

Poiésis, Niterói, v. 20, n. 33, jan./jun. 2019. 